\title{
Algunas consideraciones de epidemiología e inmunopatología de la peste porcina clásica
}

\author{
Jefersson Stiven Salgado-Ruíz ${ }^{凶 \mathbb{0} ;}$; Dumar Alexander Jaramillo-Hernández ${ }^{2 *} \bowtie \mathbb{0}$.
}

\begin{abstract}
${ }^{1}$ Universidad de los Llanos, Facultad de Ciencias Agropecuarias y Recursos Naturales, Escuela de Ciencias animales, Programa de Medicina Veterinaria y Zootecnia. Villavicencio, Colombia.

2Universidad de los Llanos, Facultad de Ciencias Agropecuarias y Recursos Naturales, Escuela de Ciencias Animales, Grupo de investigación en Farmacología experimental y Medicina interna - Élite. Villavicencio, Colombia.

*Correspondencia: dumar.jaramillo@unillanos.edu.co
\end{abstract}

Recibido: Abril 2021; Aceptado: Septiembre 2021; Publicado: Diciembre 2021.

\section{RESUMEN}

La peste porcina clásica (PPC) es una enfermedad causada por un virus ARN de la familia Flaviviridae, genero Pestivirus conocido como Pestivirus C. En la actualidad se conoce su distribución mundial y es causante de grandes pérdidas económicas en las producciones porcícolas. Sus únicos reservorios naturales son el cerdo y el jabalí. El objetivo de esta revisión es presentar una actualización sobre algunos aspectos relevantes epidemiológicos e inmunopatológicos de la PPC. La PPC es una enfermedad de notificación obligatoria para Colombia y los animales persistentemente infectados son la clave para su diseminación y endemicidad. La infección por el virus de la PPC se caracteriza por coagulación intravascular diseminada, trombocitopenia e inmunosupresión, dependiendo en severidad por la virulencia de las distintas cepas. El virus tiene afinidad por monocitos/macrófagos y células endoteliales vasculares donde tiene la capacidad de inducir diferentes mecanismos celulares que le permiten proliferar y persistir en el animal como lo son: el estrés oxidativo al incrementar los niveles de especies reactivas de oxígeno que genera una disminución de la biodisponibilidad de óxido nítrico; la fisión mitocondrial que permite una supervivencia celular por la inhibición de la apoptosis; y la inmunosupresión debido a la depleción de linfocitos $\mathrm{T}$ y $\mathrm{B}$ creada por la piroptosis en función de la gasdermina-D en órganos linfoides periféricos que reduce la respuesta inmune humoral y celular. El entendimiento inmunopatológico desde la explicación molecular en la PPC es importante en el aporte conceptual del desarrollo de nuevas estrategias profilácticas y terapéuticas que permitan controlar/ erradicar esta enfermedad.

Palabras clave: Enfermedad transmisible; inmunología; estrés oxidativo; piroptosis; virología (Fuente: DeCS).

\section{ABSTRACT}

Classical swine fever (CSF) is a disease caused by RNA virus, Flaviviridae family, genus Pestivirus, known as Pestivirus $C$. At present its worldwide distribution is known and is the cause of great economic losses in pig production. Its only natural reservoirs are pigs and wild boar. The aim of this review is to present an update on some relevant epidemiological and immunopathological 
aspects of CSF. CSF is a notifiable disease for Colombia and persistently infected animals are the key to its spread and endemicity. CSF virus infection is characterized by disseminated intravascular coagulation, thrombocytopenia, and immunosuppression, depending on severity due to the virulence of the different strains. The virus has affinity for monocytes/macrophages and vascular endothelial cells where it has the ability to induce different cellular mechanisms that allow it to proliferate and persist in the animal, such as: oxidative stress by increasing the levels of reactive oxygen species that generates a decrease of the bioavailability of nitric oxide; mitochondrial fission that allows cell survival by inhibiting apoptosis; and immunosuppression due to the depletion of $\mathrm{T}$ and $\mathrm{B}$ lymphocytes created by pyroptosis as a function of gasdermin-D in peripheral lymphoid organs that reduces the humoral and cellular immune response. The immunopathological understanding from the molecular explanation in CSF is important in the conceptual contribution of the development of new prophylactic and therapeutic strategies that allow to control/eradicate this disease.

Keywords: Communicable diseases; immunology; oxidative stress; pyroptosis; virology (Source: $\operatorname{DeCS})$.

\section{INTRODUCCIÓN}

La peste porcina clásica (PPC) es una enfermedad porcina grave hemorrágica aguda que se caracteriza por coagulación intravascular diseminada, trombocitopenia e inmunosupresión, que provoca fiebre, leucopenia, aborto, hemorragia y una alta mortalidad en su hospedero, asociándose importantes pérdidas económicas en la producción porcina mundial (1). Esta enfermedad es causada por un virus de naturaleza ARN de cadena simple que pertenece a la familia Flaviviridae, género Pestivirus, conocido como Pestivirus C (2). La partícula vírica con envoltura tiene un diámetro aproximadamente de 40-60 nanómetros y una nucleocápside de característica icosaédrica (2). Los hallazgos patológicos más característicos en suinos con PPC son las hemorragias en el riñón, en vejiga urinaria y en los ganglios linfáticos (3). La infección puede alterar las vías metabólicas como la glucólisis, el ciclo del ácido tricarboxilico, el metabolismo de los aminoácidos y de lípidos (4). Además, el virus de la PPC ("Classical swine fever virus", CSFV) inhibe la transcripción de los genes de respuesta inmune (5).

En la actualidad, se conoce que el CSFV es de distribución mundial presentando cepas de diferente virulencia que ocasionan gran impacto en la economía de las producciones porcícolas debido a su alta tasa de morbilidad, mortalidad y los consecuentes riesgos sanitarios que conlleva esta enfermedad enlistada en las enfermedades de reporte obligatorio de la Organización Internacional de Sanidad Animal (OIE) (6) y por supuesto adoptada como enfermedad de notificación obligatoria en Colombia (Resolución ICA Nº2129 de 2002).
Aun cuando se ha estipulado la vacunación como pilar fundamental de los planes de prevención de la PPC, el CSFV ha evolucionado a tal punto de generar hospederos persistentemente infectados que inmortalizan dentro del sistema de producción porcino la posibilidad de presentación de brotes de la enfermedad (7). Por esta razón es imprescindible estudiar los procesos inmunopatológicos del CSFV, con la finalidad de sustentar las bases de desarrollos de nuevos fármacos y vacunas específicas para la prevención, el control y la erradicación de esta enfermedad.

El objetivo de este artículo es la presentación de un contexto general de la epidemiologia mundial y de Colombia de la PPC, de la misma forma y con un especial énfasis en la comprensión de los mecanismos inmunopatológicos actualmente estudiados del CSFV enfocados a la generación de animales persistentemente infectados.

\section{Aspectos generales del virus de la peste porcina clásica: biología y epidemiología}

EI CSFV es ARN monocatenario y consta de una nucleocápside con una envoltura lipídica. Su genoma codifica 4 proteínas estructurales: C, Ern, E1 y E2 que son componentes del virión y 8 proteínas no estructurales p7, NS2, NS3, NS4A, NS4B, NS5A y NS5B que desempeñan diferentes funciones en la patogenia viral (8). Su tipificación genética se hace usando las regiones 5-UTR, E2 O NS5B; es así como el CSFV se clasifica en 3 genotipos los cuales se dividen entre 3 o 4 subgenotipos (9). Sin embargo, Ríos et al (10) propusieron una reclasificación con 5 genotipos y 14 subgenotipos, así: genotipo 1 (subgenotipos $1.1,1.2,1.3,1.4,1.5,1.6$ y 1.7$)$, genotipo 2 
(subgenotipos $2.1,2.2,2.3,2.4,2.5,2.6$ y 2.7 ), genotipo 3, genotipo 4 y genotipo 5 . Es importante conocer la diversidad genética del CSFV, así como su distribución mundial para la comprensión de la dinámica de la enfermedad (11).

En Latinoamérica se ha descrito principalmente el genotipo 1, en Colombia el subgenotipo 1.1 (12), igualmente en Perú, Ecuador y Brasil (13). Adicionalmente en Brasil se aislaron los subgenotipos 1.5 y 1.6 (14). En Europa y Asia está presente generalmente el genotipo 2, siendo el subgenotipo 2.1 predominante en China y el de mayor variabilidad genética (15). En Asia también está presente el genotipo 3, inicialmente se identificó en Taiwán el subgrupo 3.4; sin embargo, este fue evolucionando a otros genotipos, caso similar ocurrido en Corea del Sur (16).

Los reservorios naturales del CSFV son exclusivamente el cerdo doméstico, aquellos asilvestrados y el jabalí (17). Las rutas de transmisión son principalmente por la vía oral y oro nasal, ya sea por contacto directo con las secreciones de animales infectados siendo esta la más eficiente, o por contacto indirecto con implementos contaminados, inseminación artificial, con jabalíes circundantes o cerdos asilvestrados (18). También es posible su trasmisión por vía aerógena, por contacto con personas y alimentos contaminados $(19,20)$. Esta última vía de trasmisión es especialmente alarmante desde la perspectiva de estatus zoosanitario de los países y las facilidades de transporte de alimentos no permitidos en pasajeros aéreos, fluviales o terrestres entre países, dado que el CSFV permanece activo en el alimento (productos y subproductos de origen porcino) hasta 37 días (21).

Otra importante fuente de transmisión intraespecie es la vía vertical transplacentaria, principalmente por cepas de baja y media virulencia, causando animales persistentemente infectados (22); por la actividad de células supresoras derivadas mieloides, una población de células mieloides inmaduras capaces de disminuir la respuesta celular al interferón gamma (IFN-Y) frente a antígenos (23). Adicionalmente, se ha evidenciado lechones persistentemente infectados después de una exposición postnatal, estos lechones no muestran sintomatología, no desarrollan respuesta inmune innata ni adaptativa, pero pueden diseminar alta carga viral por medio de sus secreciones dentro de la producción, infectando los otros animales y poniendo en riesgo la granja (24).

La PPC es una enfermedad que está presente a nivel mundial, se identificó inicialmente en Estados Unidos a finales del siglo XIX, aunque se estableció que el virus se originó cuando el Virus de la Oveja Tunecina saltó a los cerdos hace aproximadamente 225 años (25). Según la OIE la enfermedad es endémica en ciertos lugares del continente asiático, europeo, en América Central y del Sur. Sin embargo, son varios los países que han logrado con éxito su control y/o erradicación; siendo estos países miembros de la OIE reconocidos libres del CSFV, entre ellos: Estados Unidos, Australia, la Unión Europea, Canadá; y en Suramérica: Argentina, Uruguay, Paraguay y Chile (Figura 1).

En Colombia la PPC fue notificada por primera vez en el año 1942. En 1980 se evidenció su gran impacto en la producción porcícola y despierta la preocupación de las autoridades nacionales (26), por esta razón y según la Ley 623 del 21 de noviembre de 2000 se declaró de "Interés Social Nacional la Erradicación de la Peste Porcina Clásica del territorio colombiano". A partir de allí y dos años después se estableció el Decreto 930 de mayo 10 de 2002, en el cual se "estableció un programa de concertación y cogestión entre los sectores público y privado para la erradicación de la Peste Porcina Clásica en todo el territorio nacional". A su vez, ese mismo año, las autoridades zoosanitarias estatales: el Instituto Colombiano Agropecuario (ICA) generó la Resolución ICA Nº2129 de septiembre 11 de 2002 "Por la cual se establecen medidas de carácter sanitario para la erradicación de la Peste Porcina Clásica".

Los efectos de la normatividad nacional para la gestión de la PPC se hicieron notables a partir del año 2008, cuando se declaran los primeros lugares libres de la enfermedad: los departamentos del Amazonas, San Andrés y Providencia. Posteriormente, en el año 2011 los departamentos de mayor producción porcícola fueron declarados libres de PPC (Caldas, Quindío, Valle del Cauca, Risaralda, Antioquia). Esto logrado por un esfuerzo conjunto, que incluyó la tecnificación de granjas e implementación de protocolos de bioseguridad (26). 


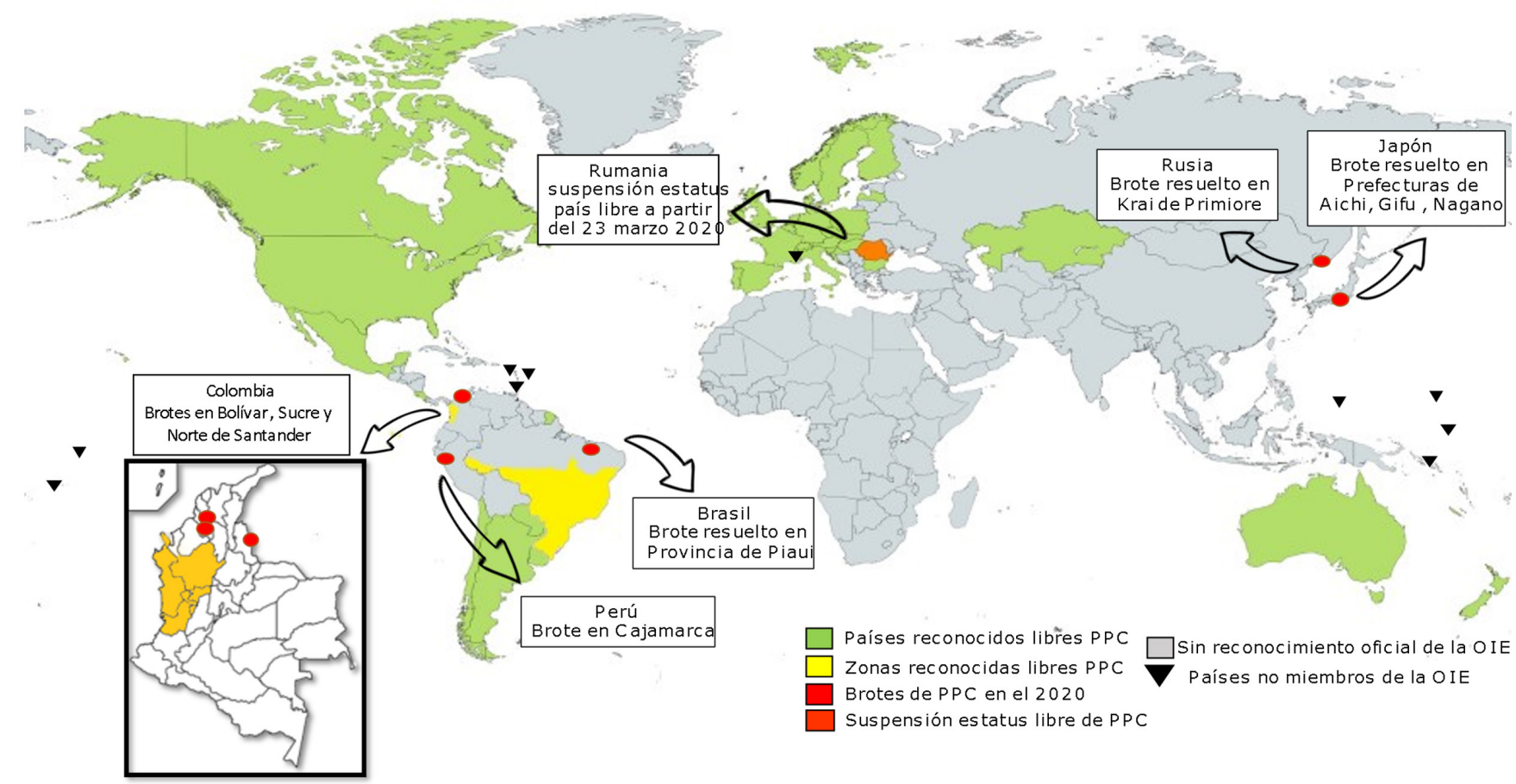

Figura 1. Mapa del estatus oficial de la peste porcina clásica en el mundo a septiembre de 2020. Países no miembros de la Organización Internacional de Sanidad Animal: Antigua y Barbuda, Granada, Islas Marshall, Islas Salomón, Kiribati, Mónaco, Nauru, Palau, Samoa, San Vicente y Las Granadinas, Tonga y Tuvalu. (PPC) peste porcina clásica; (OIE) Organización Internacional de Sanidad Animal. Fuente: autores.

Durante el periodo comprendido entre los años 2013 y 2018 fueron notificados 134 brotes de PPC en Colombia, de los cuales la mayoría ocurrieron en la región Caribe, siendo los departamentos del Magdalena y Cesar los más afectados, se conoce que el $95 \%$ de estos casos fueron documentados en cerdos de traspatio (27). Según el boletín epidemiológico ICA en el año 2020 se presentaron alertas epidemiológicas en los departamentos de Bolívar, Sucre y Norte de Santander.

\section{Peste porcina clásica: Inmunopatología}

La inmunopatología reúne una serie ordenada y sistemática de fenómenos de interacción entre el agente infeccioso y su hospedero, en relación con el sistema inmune, respuesta, regulación y efectos sistémicos o en sistemas de órganos diana del agente; comenzando desde los mecanismos de ingreso a la célula hospedera en el caso de los virus, hasta el detalle de sus efectos deletéreos directos o indirectos (ej. respuesta inmune exacerbada) (28).

\section{Infección por parte del CSFV en las células hospederas}

EI CSFV presenta afinidad, especialmente, por la línea celular monocitos-macrófagos (monocitotrópico), pero también puede replicarse en células endoteliales vasculares; entrando a la célula por diferentes vías endocíticas. El clúster de diferenciación 46 (CD46) y el heparán sulfato son los principales receptores de unión para la entrada viral (29). La vía endocítica dependiente de caveolina- 1 requiere proteínas relacionadas con Ras (Rab5 y Rab7, GTPasas pequeñas) para el transporte a los endosomas, posteriormente Rab 11 dirige el reciclaje del endosoma y finalmente se transfiere a los lisosomas mediado por una proteína de membrana asociada a lisosoma 1 (Lamp-1) donde se libera el ARN del CSFV (30).

También se ha evidenciado en estudios anteriores la endocitosis dependiente de clatrina, $\mathrm{pH}$ y colesterol, que requiere Rab5 y Rab7, y además, se ha evidenciado que Rab5 mejora la propagación viral al interactuar con la proteína no estructural 4B de los Pestivirus (NS4B) (31). La interacción del protooncogén tirosina quinasa MER (MERTK) 
con la glicoproteína E2 viral promueve la entrada del CSFV y regula la respuesta innata del hospedero (32). Adicionalmente, el gen de susceptibilidad tumoral 101 (Tsg101) en la vía del complejo de clasificación endosomal necesarios para el transporte (ESCRT-1) y su interacción con algunas proteínas no estructurales también regula la entrada y la replicación del CSFV (33). Recientemente, se determinó la importancia de la interacción de la desintegrina y metaloproteasa 17 (ADAM17) con la glicoproteína E2 dependiente de Zinc en la entrada del CSFV (34). Es ampliamente variado el mecanismo de ingreso del CSFV al monocitomacrófago, sustentado en su proceso altamente evolutivo y adaptativo a sus hospederos.

Posterior al ingreso a la célula hospedera, la replicación del CSFV induce estrés oxidativo al aumentar los niveles de especies reactivas de Oxígeno (ROS) intracelularmente (35); como respuesta a esta situación, la célula infectada aumenta los niveles de antioxidantes, como la tiorredoxina (Trx), peroxiredoxina- 6 (PRDX-6) y hemo oxigenasa-1 (HO-1), para la atenuación del estrés oxidativo creciente. Sin embargo, estos mecanismos antioxidantes llegan a ser insuficientes frente a la infección viral (36). Además, se suman a esta situación de estrés celular, altas concentraciones de ciclooxigenasa-2 (COX-2), y a su vez, disminución de receptor gamma activado por el proliferador de proteína antiinflamatoria (PPAR-y), acciones que contribuye a la respuesta inflamatoria y la disfunción de la célula hospedera (ej. endotelial) en el proceso infeccioso por el CSFV (37).

He et al (36) utilizaron inhibidores del estrés oxidativo en células infectadas por el CSFV, donde encontró concentraciones bajas de ARN viral, acción que demostró la importancia del estrés oxidativo como factor participativo en la replicación del CSFV. Un ejemplo de estos inhibidores, es la sobreexposición con Trx que crea una interacción con la proteína $\mathrm{E}$ viral, lo cual inhibe la replicación del CSFV a través de la vía factor nuclear $\mathrm{k} B$ (NF-kB), mostrando una posible estrategia terapéutica - inmmunoprofiláctica contra el inicio de la patogénesis molecular del CSFV (38).

En células endoteliales infectadas con aumento de niveles de ROS, se reduce la biodisponibilidad del óxido nítrico (NO) por medio de reacciones bioquímicas que generan la formación de peroxinitrito. Este metabolito desacopla la enzima óxido nítrico sintasa endotelial (NOSe) dando como resultado la formación del anión superóxido (37). Aunque el NO reducido finalmente causa una serie de reacciones relacionadas con la disfunción endotelial responsable de las principales consecuencias clínicas de la infección (Figura 2), su menor concentración también podría representar respuestas inmunes innatas más débiles del hospedero contra el CSFV. Además, Zaffuto et al (38) demostraron que en macrófagos infectados también se presenta niveles bajos de NO y niveles altos de arginasa-1 (inhibidor de la producción de NO), potencializando el estrés oxidativo y la actividad del CSFV.

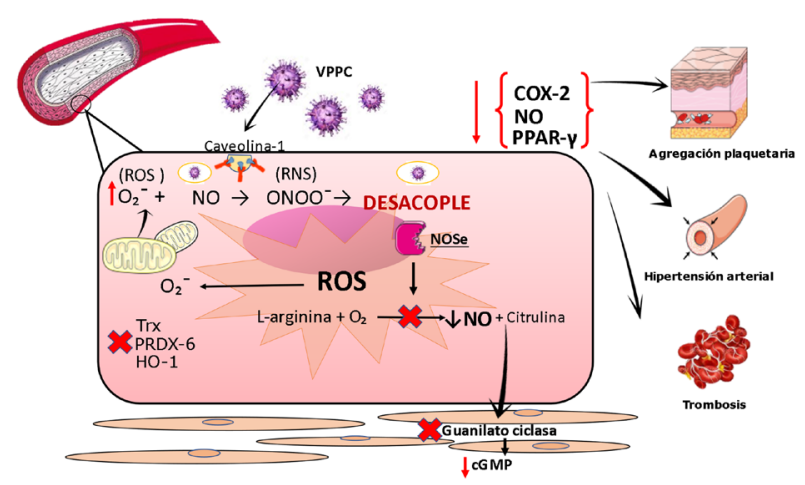

Figura 2. Mecanismos de estrés oxidativo en la célula endotelial infectada por el virus de la peste porcina clásica (CSFV). Fuente: autores El CSFV puede ingresar a la célula endotelial a través de endocitosis mediada por caveolina-1. La replicación viral induce estrés oxidativo, donde la mitocondria juega un papel preponderante y las enzimas antioxidantes (ej. Trx, PRDX-6 y HO-1) se ven sobrepasadas en su capacidad vital de detoxificación. El acúmulo de ROS y RNS genera alteración en la funcionalidad de la NOSe dando como consecuencia la caída en la concentración de NO. La alteración en la biodisponibilidad de NO, sumado a la baja actividad enzimática de COX-2 y menor expresión de PPAR-Y en el endotelio arteriolar, agravada con la alteración funcional de la Guanilato ciclasa (menor concentración de cGMP), se asocia a disfunción endotelial y sus diversas consecuencias clínicas de la peste porcina clásica: trombosis, hipertensión arterial y agregación plaquetaria. (cGMP) Guanosin monofosfato cíclico; (COX2) ciclooxigenasa-2; (PPAR-y) receptor gamma activado por el proliferador de proteína antiinflamatoria; (ROS) especies reactivas de Oxígeno; (RNS) especies reactivas de Nitrógeno; $\left(\mathrm{O}_{2}\right)$ superóxido, (NO) óxido nítrico, (ONOO) Peróxinitrito; (NOSe) óxido nítrico sintasa endotelial; (Trx) tiorredoxina; (PRDX-6) peroxiredoxina-6; (HO-1) hemo oxigenasa-1. 


\section{Factores de virulencia del CSFV y el inmunocompromiso del hospedero}

A parte de los efectos del estrés oxidativo per se por la replicación viral al interior de la célula infectada, el CSFV posee una serie de factores de virulencia de relevancia para su proceso patogénico que atañen de forma directa el sistema inmune de su hospedero. Iniciando por los efectos sobre el sistema inmune innato, donde la NS4B suprime la señalización del receptor tipo-Toll 3 (TLR 3) por ende se afecta la transcripción de diversos factores de transcripción nuclear (ej. TRIF, IRF3 y NF-kB) que son esenciales en el orquestamiento de la respuesta protectora a partir de interferón (IFN) y otras citoquinas (39) (Figura 3.2). El NF-kB es una familia de factores de transcripción que regulan un gran número de genes importantes en la actividad del sistema inmune innato y adaptativo como mediador de la respuesta inflamatoria, algunos virus usan la activación de NF-kB a favor de su replicación viral mientras otros virus inhiben su activación como un mecanismo útil para evadir la respuesta inmune (40).

Chen et al (40) demostraron a partir de estudios con modelos celulares in vitro e in vivo con células mononucleares de animales infectados, que la infección por el CSFV no activa el NF-kB, posiblemente como un mecanismo de evasión viral del sistema inmune, promoviendo así, la propagación viral. Además, estudios más recientes de Dong y Tang (41) demostraron que la proteína viral NS5A probablemente suprimía la actividad proinflamatoria celular por medio de la inhibición de las vías de señalización del NF-kB.

Otra ruta de transducción de señales importante en el sistema inmune es la ruta de los transductores de señal/Janus quinasa y activadores de la transcripción (JAK-STAT) involucrada en la activación de aproximadamente 40 citoquinas (42). En estudios realizados por Wang et al (43) demostraron en células renales porcinas la interacción de la proteína E2 del CSFV con la proteína quinasa activada por mitógeno (MEK) que por un mecanismo aún por clarificar, puede generar la inhibición de la ruta JAK-STAT dando como resultado una mayor replicación del CSFV.

Mientras el CSFV inactiva unas vías de señalización celular, puede activar otras; es así, que en células infectadas por CSFV se presentaron concentraciones altas de expresión de interleucina (IL) 1 (IL-1), IL-6 e IL-8, con un pico mayor a las 2 horas de exposición. Donde la IL-1 es altamente relevante en la activación de un número de citocinas proinflamatorias secretadas por células endoteliales y principalmente monocitos/macrófagos infectados (44). Jinghan et al (45) demostraron con cepas de diferente virulencia del CSFV, que la infección viral induce la secreción de diferentes citoquinas como el factor necrosis tumoral (TNF-a), IL-2, IL-4, IL-6 e IL-10 con diferencias en sus expresiones por la respuesta a la infección entre las distintas cepas.

Por otro lado, la infección por CSFV estimula la secreción de IL-1 $\beta$ e IL-18, citocinas que son componentes importantes del sistema inmune innato frente a invasión viral. La maduración de pro-IL-1 $\beta$ es mediada por la enzima caspasa 1 , la cual es procesada gracias a la activación del inflamasoma NRLP3 en monocitos/macrófagos infectados $(46,47)$. Según Lin et al $(46)$ este mecanismo de secreción de IL-1 $\beta$ por parte de la célula hospedera del CSFV es inducido por la viroporina P7 viral, la cual actúa como canal iónico dependiente de calcio en el retículo endoplasmático, su función más estudiada es la de generar una permeabilización de la membrana celular para facilitar la salida de partículas víricas infecciosas (Figura 3.3).

En estudios realizados in vitro con células dendríticas se determinó que el CSFV no altera las características morfológicas ni funcionales de esta célula, y su capacidad de presentar antígeno al linfocito $T$ queda intacta sirviendo como un mecanismo de diseminación del virus a los tejidos linfoides periféricos, donde generalmente induce posterior a su ingreso a estas líneas celulares, una piroptosis de células linfoides; lo que resume la linfopenia y la consecuente inmunosupresión del hospedero (48).

En consecuencia, los animales infectados por el CSFV presentan una disminución en la respuesta del sistema inmune adaptativo, tanto de la respuesta inmune humoral mediada por células T CD4+ que reconocen el antígeno presentado por el complejo mayor de histocompatibilidad (MHC) clase II (MHC II) que normalmente estimula la activación, maduración y secreción de anticuerpos por parte de linfocitos B; como de la respuesta inmune celular mediada por células T CD8+ o células $T$ citotóxicas, que por medio de una unión de su receptor con el antígeno presentado por el MHCI se encarga de la destrucción de células infectadas por el virus (45). Esta acción asociada a sus factores de virulencia genera inmunosupresión del hospedero, con una alta predisposición a infecciones secundarias principalmente en el sistema respiratorio y digestivo de origen bacteriano. 


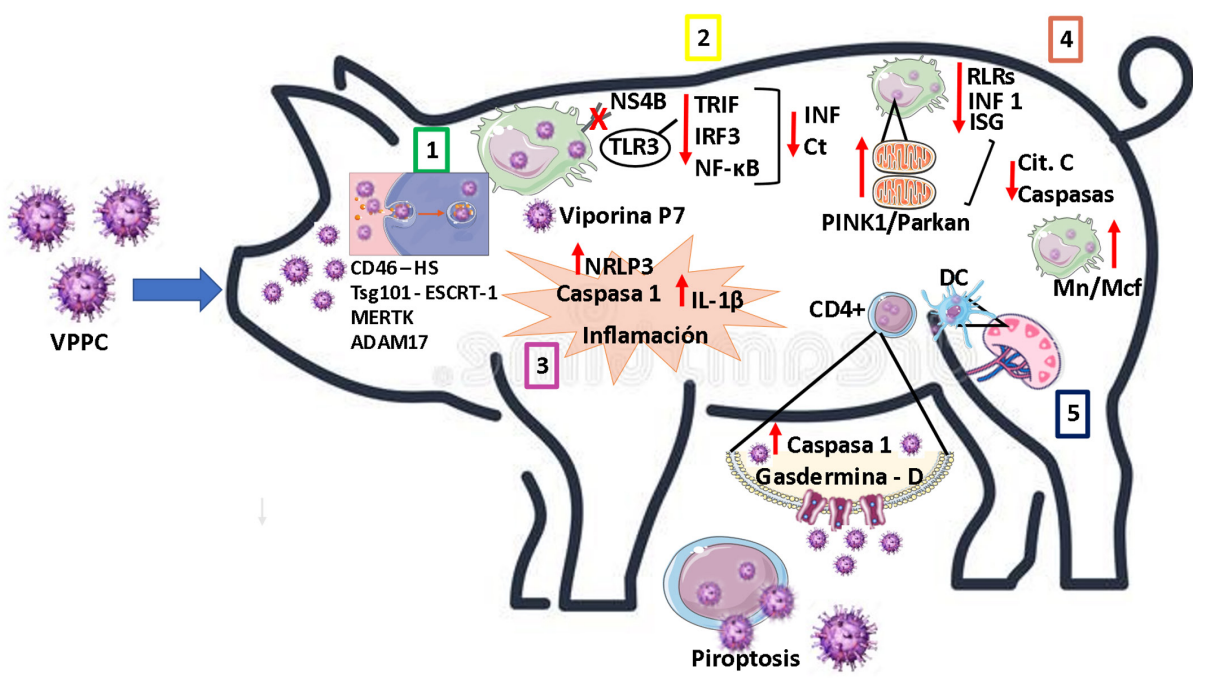

Figura 3. Mecanismos inmunopatológicos del virus de la peste porcina clásica (CSFV). 1. Fuente: autores. EI CSFV presenta diferentes vías endocíticas para la entrada a la célula hospedera, a través de CD46 y HS como vías clásicas de endocitosis, entre otras (Tsg101 - ESCRT-1, ADAM17, MERTK) a células Mn/Mcf, dado su monocitotrópismo. 2. NS4B como factor de virulencia del CSFV juegan un papel preponderante en el Mn/Mcf infectado, dado que inhibe el TRL3, sin la activación de esta vía de inmunidad innata es imposible la activación de procesos de transcripción (ej. TRIF, IRF3, NF-kB) asociados a vías de respuesta celular a infección viral (IFN,Ct). 3. Por su parte, la viporina P7 induce en el Mn/Mcf la secreción de citocinas, entre estas la más importante IL-1B, quien estimulará al inflamasoma NRLP3 y su subsecuente respuesta inflamatoria. 4. En el Mn/Mcf infectado el CSFV a través de la inhibición de RLRs pasa desapercibido por los procesos de reconocimiento de RNA extraño a la célula hospedera, lo cual promueve una inhibición de producción de IFN 1 e ISG, sumado a esto, los mecanismos de fisión mitocondrial y mitofagia generan una disminución de proteínas pre-apoptóticas (Cit. C y Caspasas) concluyendo en Mn/Mcf infectados e inmortales. 5. En ganglios linfáticos, las DC infectadas con el CSFV interactúan con células linfoides (ej. CD4+) en el proceso de presentación de antígeno, situación que favorece la diseminación viral en otros células hospederas, además de promover en los linfocitos expuestos mecanismos de piroptosis mediados por caspasa 1 y gasdermina D. (Ct) citocinas; (CD46) clúster de diferenciación 46; (CD4+) linfocito CD4+; (Cit. C) citocromo C; (DC) célula dendrítica; (NF-kB) factor nuclear Kappa B; (TRIF, IRF3) factores de transcripción nuclear; (IL) interleucinas; (IL-1B) interleucina 1B; (IFN) interferón; (IFN 1) interferón tipo 1; (Mn/Mcf) monocitos-macrófagos; (ISG) gen estimulado por IFN; (NF-kB) factor nuclear kappa B; (NS4B) proteína no estructural 4B de los Pestivirus; (NRLP3) inflamasoma NRLP3; (MERTK) protooncogén tirosina quinasa MER (Tsg101) gen de susceptibilidad tumoral 101; (ESCRT-1) complejo de clasificación endosomal necesarios para el transporte; (ADAM17) metaloproteasa 17; (RLRs) receptores tipo gen I inducible por ácido retinóico; (PINK1/Parkin) vía quinasa putativa 1 inducida por PTEN y E3 ubiquitina ligasa; (CSFV) virus de la peste porcina clásica.

\section{Mecanismos inmunopatológicos del CSFV responsables de los animales persistentemente infectados}

La fisión mitocondrial genera una división de la mitocondria a dos mitocondrias hijas, siendo un mecanismo esencial para el funcionamiento normal de la célula frente a situaciones de estrés metabólico o ambiental por medio del mantenimiento de los mecanismos bioenergéticos (49). Además, este mecanismo permite la segregación de componentes proteícos, lipídicos y ADN de la mitocondria para su respectiva eliminación con el fin de mantener un número de mitocondrias renovadas (50). El CSFV induce este mecanismo de la fisión mitocondrial y la posterior fragmentación y autofagia selectiva de las mitocondrias (mitofagia) regulado por la vía quinasa putativa 1 inducida por PTEN (PINK1) y E3 ubiquitina ligasa (Parkin) (PINK1/Parkin) en la activación del estrés sobre el retículo endoplasmático por su contacto dinámico con las mitocondrias (51). Esta situación origina en las células infectadas por el CSFV una inhibición de la vía intrínseca o mitocondrial de la apoptosis, generando una baja en la liberación de proteínas pro-apoptóticas como la citocromo $\mathrm{C}$ y por ende una disminución en la activación de caspasas que normalmente funcionarían en el proceso de apoptosis $(49,50)$ (Figura 3.4).

Pei et al (52) sugieren que esto ocurre por una regulación en los niveles de producción de IFN 
tipo I debido a una limitación de la señalización en los receptores tipo gen I inducible por ácido retinóico (RIG-I) (RLRs), los cuales son responsables de la identificación de patrones moleculares tipo RNA asociados a virus y su respectiva activación del sistema inmune innato (53), que lleva a una inhibición de la expresión del gen estimulado por INF (ISG) asociados a la apoptosis. Es decir, la mitofagia inducida por el CSFV inhibe la activación de la apoptosis, mecanismo conocido como una vía importante de protección en células infectadas, que al ser inhibido promueve la supervivencia celular facilitando la replicación y la persistencia de la infección viral en el animal (52) (Figura 3.4).

Otra de las acciones del CSFV para inducir estados de inmunosupresión de su hospedero es la inducción de la piroptosis en linfocitos $T$ y $B$ de órganos linfoides periféricos, acción mediada a través de la activación de la caspasa 1 (54). Así mismo, se ha determinado la activación de gasdermina-D como factor mediador de la piroptosis en la inmunopatología de la PPC (55). La gasdermina-D que es escindida por la actividad de capasa-1 induce este tipo de muerte celular cuando se dirige rápidamente a la membrana plasmática uniéndose a liposomas con la consecuente formación de grandes poros de permeabilidad (56), esto genera una alteración de los gradientes iónicos celulares lleva a un flujo de agua, con tumefacción celular y lisis osmótica, liberando el contenido celular (57) (Figura 3.5).

\section{CONSIDERACIONES FINALES}

En animales infectados por el CSFV, la respuesta inmune innata es aprovechada por este para su replicación y persistencia en el hospedero por medio de la inducción de diferentes mecanismos celulares como lo son: el estrés oxidativo, la inhibición de las rutas de transducción, la fisión mitocondrial con la posterior mitofagia y la consecuente inhibición de la apoptosis que permite la supervivencia celular y la posibilidad de generar animales persistentemente infectados, siendo estos cruciales para la endemicidad viral dentro del sistema de producción porcino y futuros brotes de PPC en ventanas inmunológicas aun bajo esquemas de vacunación rigurosos (50).

Una de las consecuencias inmunopatológicas del CSFV en sus hospederos es la inmunosupresión, la cual es causada por el mecanismo de piroptosis en los órganos linfoides periféricos que genera animales infectados inmunocomprometidos, situación que en algunas ocasiones dificulta su diagnóstico o puede exacerbar la PPC al concomitar con otras infecciones, por ejemplo, el virus del Síndrome Respiratorio y Reproductivo
Porcino, Circovirus Porcino e infecciones secundarias, como Glaesserela parasuis, Pasteurella multocida, entre otras (54).

La elevada tasa de morbilidad y mortalidad del CSFV está asociada a grandes pérdidas económicas, tanto en países donde la mayoría de la producción porcina es industrializada, como en los países donde este reglón productivo es mantenido por la producción familiar y de traspatio; afectando así la comercialización - exportación de sus productos cárnicos y derivados, como también la economía familiar, respectivamente. Por ende, es crucial la implementación de diferentes estrategias de control de la PPC desde una estricta vigilancia, procesos de zonificación, inmunización preventiva, sacrificio de animales infectados y el cumplimiento de la reglamentación sanitaria correspondiente (58).

La necesidad de desarrollar nuevas vacunas más eficientes frente al CSFV ha permitido realizar investigaciones alrededor de la importancia de diferenciar los animales infectados de los vacunados, siendo esta actividad imposible de desarrollar a través de pruebas diagnósticas serológicas. De allí la creación de vacunas marcadoras de animales inoculados: como las vacunas de subunidad E2 con adyuvante molecular, vacunas quiméricas, vacunas de replicones y vectores virales. Además, a futuro el desarrollo de vacunas con epítopos podría cubrir un alto grupo de cepas virales, hasta aquellas emergentes que escapan de la respuesta de vacunas actuales. Estas cepas emergentes son el resultado de un proceso evolutivo influenciado por presión selectiva viral asociada a procesos de vacunación extensa en diferentes regiones del mundo (59). Otras estrategias antivirales con base al conocimiento de estos mecanismos inmunopatológicos es el desarrollo de nuevas tecnologías que involucran cerdos transgénicos resistentes a la PCC con la capacidad de transmitir esa característica a la descendencia (60).

Por último, los diferentes avances en la investigación para el entendimiento inmunopatológico de la PPC, que de igual manera formulan preguntas para posibles estudios a futuro, son de total importancia en el aporte de nuevas estrategias para la prevención y el control de la enfermedad mediante diferentes mecanismos inmunoprofilácticos u otros medios terapéuticos desde el entendimiento molecular de la patogénesis.

\section{Conflicto de interés}

Los autores declaran no tener ningún conflicto de intereses por el envío de este manuscrito. 


\section{REFERENCIAS}

1. Kleiboeker SB. Swine fever: classical swine fever and African swine fever. Vet Clin North Am Food Anim Pract. 2002; 18(3):431451. https://doi.org/10.1016/S07490720(02)00028-2

2. Smith DB, Meyers G, Bukh J, Gould EA, Monath T, Scott Muerhoff A, et al. Proposed revision to the taxonomy of the genus Pestivirus, family Flaviviridae. J Gen Virol. 2017; 98(8):2106-2112. https://doi. org/10.1099/jgv.0.000873

3. Elbers AR, Vos JH, Bouma A, van Exsel AC, Stegeman A. Assessment of the use of gross lesions at post-mortem to detect outbreaks of classical swine fever. Vet Microbiol. 2003; 96(4):345-356. https://doi.org/10.1016/j. vetmic.2003.09.005

4. Gong W, Jia J, Zhang B, Mi S, Zhang L, Xie $X$, et al. Serum metabolomic profiling of piglets infected with virulent classical swine fever virus. Front Microbiol. 2017; 8:731. https://doi.org/10.3389/fmicb.2017.00731

5. Feng L, Li XQ, Li XN, Li J, Meng X, Zhang H, et al. In vitro infection with classical swine fever virus inhibits the transcription of immune response genes. Virology J. 2012; 9(1):1-11. https://doi.org/10.1186/1743$\underline{422 X-9-175}$

6. OIE. World organisation for animal health. Clasical swine fever. Technical.Disease Cards; 2020. https://www.oie.int/fileadmin/Home/ eng/Animal Health in the World/docs/pdf/ Disease cards/CLASSICAL SWINE FEVER.pdf

7. Sun J, Shi Z, Guo H, Tu C. Changes in the porcine peripheral blood mononuclear cell proteome induced by infection with highly virulent classical swine fever virus. J Gen Virol. 2010; 91(9):2254-2262. https://doi. org/10.1099/vir.0.022020-0

8. Meyers G, Rümenapf T, Thiel HJ. Molecular cloning and nucleotide sequence of the genome of hog cholera virus. Virology. 1989; 171(2):555-567. https://doi. org/10.1016/0042-6822(89)90625-9
9. Paton D, McGoldrick A, Greiser-Wilke I, Parchariyanon S, Song J, Liou PP, Belak S. Genetic typing of classical swine fever virus. Vet Microbiol. 2000; 73(2-3):137157. https://doi.org/10.1016/S03781135(00)00141-3

10. Rios L, Núñez JI, Díaz de Arce $H$, Ganges $L$, Pérez L. Revisiting the genetic diversity of classical swine fever virus: A proposal for new genotyping and subgenotyping schemes of classification. Transbound Emerg Dis. 2018; 65(4):963-971. https://doi. org/10.1111/tbed.12909

11. Beer M, Goller K, Staubach C, Blome S. Genetic variability and distribution of Classical swine fever virus. Anim Health Res Rev. 2015; 16(1):33. https://doi.org/10.1017/ $\underline{\mathrm{S} 1466252315000109}$

12. Sabogal Z, Mogollón J, Rincón M, Clavijo A. Phylogenetic analysis of recent isolates of classical swine fever virus from Colombia. Virus Res. 2006; 115(1):99-103. https:// doi.org/10.1016/j.virusres.2005.06.016

13. Pereda A, Greiser Wilke I, Schmitt B, Rincon M, Mogollon JD, Sabogal Z, et al. Phylogenetic analysis of classical swine fever virus (CSFV) field isolates from outbreaks in South and Central America. Virus Res. 2005; 110(1-2):111-118. https://doi. org/10.1016/j.virusres.2005.01.011

14. Silva $M N$, Silva $D$, Leite $A S$, Gomes $A L$, Freitas AC, Pinheiro-Junior J, Jesus AL. Identification and genetic characterization of classical swine fever virus isolates in Brazil: a new subgenotype. Arch Virol. 2017; 162(3):817-822. https://doi.org/10.1007/ $\underline{\mathrm{s} 00705-016-3145-8}$

15. Gong W, Wu J, Lu Z, Zhang L, Qin S, Chen F, et al. Genetic diversity of subgenotype 2.1 isolates of classical swine fever virus. Infect Genet Evol. 2016; 41:218-226. https://doi. org/10.1016/j.meegid.2016.04.002

16. An D, Lim S, Choe S, Kim K, Cha R, Cho I, et al. Evolutionary dynamics of classical swine fever virus in South Korea:1987-2017. Vet Microbiol. 2018; 225:79-88. https://doi. org/10.1016/j.vetmic.2018.09.020 
17. Depner K, Müller A, Gruber A, Rodriguez A, Bickhardt K, Liess B. Classical swine fever in wild boar (Sus scrofa) experimental infections and viral persistence. DTW. Dtsch Tierarztl Wochenschr. 1995; 102(10):381-384. https://pubmed.ncbi.nlm.nih.gov/8591736/

18. Schulz K, Staubach C, Blome S. African and classical swine fever: similarities, differences and epidemiological consequences. Vet. Res. 2017; 48(1):1-13. https://doi.org/10.1186/ s13567-017-0490-x

19. Weesendorp E, Stegeman A, Loeffen WL. Quantification of classical swine fever virus in aerosols originating from pigs infected with strains of high, moderate or low virulence. Vet Microbiol. 2009; 135(34):222-230. https://doi.org/10.1016/j. vetmic. 2008.09.073

20. Bøtner $A$, Belsham G.Virus survival in slurry: analysis of the stability of foot-and-mouth disease, classical swine fever, bovine viral diarrhoea and swine influenza viruses. Vet Microbiol. 2012; 157(1-2):41-49. https:// doi.org/10.1016/j.vetmic.2011.12.010

21. Stoian A, Petrovan V, Constance L, Olcha M, Dee S, Diel D, et al. Stability of classical swine fever virus and pseudorabies virus in animal feed ingredients exposed to transpacific shipping conditions. Transbound Emerg Dis. 2020; 67(4):1623-1632. https://doi.org/10.1111/tbed.13498

22. Cabezón O, Colom Cadena A, Muñoz González S, Pérez Simó M, Bohórquez J, Rosell R, et al. Postnatal Persistent Infection With Classical Swine Fever Virus in Wild Boar: ¿A Strategy for Viral Maintenance? Transbound Emerg Dis. 2017; 64(2):651655. https://doi.org/10.1111/tbed.1239

23. Bohorquez J, Muñoz González S, Pérez Simó M, Revilla C, Domínguez J, Ganges L. Identification of an immunosuppressive cell population during classical swine fever virus infection and its role in viral persistence in the host. Viruses. 2019; 11(9):822. https:// doi.org/10.3390/v11090822
24. Bohórquez J, Wang $M$, Pérez Simó $M$, Vidal E, Rosell R, Ganges L. Low CD4/CD8 ratio in classical swine fever postnatal persistent infection generated at 3 weeks after birth. Transbound Emerg Dis. 2019; 66(2):752 762. https://doi.org/10.1111/tbed.13080

25. Rios L, Coronado L, Naranjo D, Martínez O, Perera $C$, Hernandez $L$, et al. Deciphering the emergence, genetic diversity and evolution of classical swine fever virus. Sci Rep. 2017; 7(1):1-18. https://doi. org/10.1038/s41598-017-18196-y

26. ICA. Programa de Erradicación Peste Porcina Clásica. Instituto Colombiano Agropecuario: Colombia; 2018. https://www.ica.gov. co/getdoc/ea9c6aa0-a5fc-472f-869b975b27d7ac35/peste-porcina-clasica-(1). aspx

27. Pineda $P$, Deluque A, Peña M, Diaz O, Allepuz A, Casal J. Descriptive epidemiology of classical swine fever outbreaks in the period 2013-2018 in Colombia. PloS One. 2020; 15(6):e0234490. https://doi.org/10.1371/ journal.pone.0234490

28. Katz DR. Recent developments in immunopathology. Second Edition. in Encyclopedia of Immunology Delves PJ, Roitt IM. Academic Press; 1998. https:// doi.org/10.1006/rwei.1999.0342

29. Dräger C, Beer M, Blome S. Porcine complement regulatory protein CD46 and heparan sulfates are the major factors for classical swine fever virus attachment in vitro. Arch Virol. 2015; 160(3):739-746. https://doi.org/10.1007/s00705-0142313-y

30. Zhang Y, Liu Y, Xiao F, Liu C, Liang X, Chen J, et al. Rab5, Rab7, and Rab11 are required for caveola-dependent endocytosis of classical swine fever virus in porcine alveolar macrophages. J Virol. 2018; 92(15):e0079718. https://doi.org/10.1128/JVI.00797-18

31. Shi B, Liu C, Zhou J, Wang S, Gao Z, Zhang $X$, et al. Entry of classical swine fever virus into $\mathrm{PK}-15$ cells via a $\mathrm{pH}-$, dynamin, and cholesterol-dependent, clathrin-mediated endocytic pathway that requires Rab5 and Rab7. J Virol. 2016; 90(20):9194-9208. https://doi.org/10.1128/JVI.00688-16 
32. Zheng G, Li L, Zhang Y, Qu L, Wang W, $\mathrm{Li} M$, et al. MERTK is a host factor that promotes classical swine fever virus entry and antagonizes innate immune response in PK-15 cells. Emerg Microbes Infect. 2020; 9(1):571-581. https://doi.org/10.1080/22 $\underline{221751.2020 .1738278}$

33. Liu C, Liu Y, Cheng Y, Zhang Y, Zhang J, Liang $X$, et al. The ESCRT-I Subunit Tsg101 Plays Novel Dual Roles in Entry and Replication of Classical Swine Fever Virus. J Virol. 2021; 95(6):e01928-20. https://doi.org/10.1128/ JVI.01928-20

34. Yuan F, Li D, Li C, Zhang $Y$, Song H, Li S, et al. ADAM17 is an essential attachment factor for classical swine fever virus. PLoS Pathog. 2021; 17(3):e1009393. https://doi. org/10.1371/journal.ppat.1009393

35. Kataria AK, Kataria N. Evaluation of oxidative stress in pigs affected with classical swine fever. Porcine Res. 2012; 2(2):35-38. http://www. porc.bioflux.com.ro/docs/2012.35-38.pdf

36. He L, Zhang Y, Fang Y, Liang W, Lin J, Cheng M. Classical swine fever virus induces oxidative stress in swine umbilical vein endothelial cells. BMC Vet Res. 2012; 10(1):1-9. https:// doi.org/10.1186/s12917-014-0279-3

37. Li S, Wang J, He WR, Feng S, Li Y, Wang X, et al. Thioredoxin 2 is a novel E2-interacting protein that inhibits the replication of classical swine fever virus. J Virol. 2015; 89:8510-8524. https://doi.org/10.1128/ JVI.00429-15

38. Zaffuto $K$, Piccone $M$, Burrage $T$, Balinsky C, Risatti G, Borca M, et al Classical swine fever virus inhibits nitric oxide production in infected macrophages. J Gen Virol.2007; 88(11):3007-3012. https://doi. org/10.1099/vir.0.83042-0

39. Cao Z, Yang Q, Zheng M, Lv H, Kang K, Zhang Y. Classical swine fever virus nonstructural proteins modulate Toll-like receptor signaling pathways in porcine monocyte-derived macrophages. Vet Microbiol. 2019; 230:101-109. https://doi. org/10.1016/j.vetmic.2019.01.025
40. Chen L, Dong $X$, Zhao $M$, Shen $H$, Wang $\mathrm{J}$, Pei J, et al. Classical swine fever virus failed to activate nuclear factor-kappa b signaling pathway both in vitro and in vivo. Virol J. 2012; 9(1):1-8. https://doi. org/10.1186/1743-422X-9-293

41. Dong $X$, Tang S. Classical swine fever virus NS5A protein changed inflammatory cytokine secretion in porcine alveolar macrophages by inhibiting the NF-KB signaling pathway. Virol J. 2016; 13(1):19. https://doi.org/10.1186/s12985-0160545-z

42. Tizard IR. Introducción a la inmunología veterinaria, octava edición. capitulo sexto; señalización celular: las citoquinas y sus receptores; ruta de transducción de señales: La ruta de JAK-STAT. ELSEVIER; 2009.

43. Wang J, Chen S, Liao Y, Zhang E, Feng S, Yu $S$, et al. Mitogen-activated protein kinase 2, a novel E2-interacting protein, promotes the growth of classical swine fever virus via attenuation of the JAK-STAT signaling pathway. J Virol. 2016; 90(22):10271-10283. https://doi.org/10.1128/JVI.01407-16

44. Bensaude E, Turner JL, Wakeley PR, Sweetman DA, Pardieu C, Drew TW, et al. Classical swine fever virus induces proinflammatory cytokines and tissue factor expression and inhibits apoptosis and interferon synthesis during the establishment of long-term infection of porcine vascular endothelial cells. J Gen Virol.2004; 85(4):1029-1037. https://doi. org/10.1099/vir.0.19637-0

45. Jinghan $W$, Yuan $S$, Meng $X-Y u$, Lian-Feng $L$, Yongfeng $L$, Yuzi L,Wenjing $W$, et al. Comprehensive evaluation of the host responses to infection with differentially virulent classical swine fever virus strains in pigs. Virus Res. 2018; 255:68-76. https:// doi.org/10.1016/j.virusres.2018.06.012

46. Lin Z, Liang $W$, Kang K, Li H, Cao Z, Zhang $Y$. Classical swine fever virus and $p 7$ protein induce secretion of IL-1 $\beta$ in macrophages. J Gen Virol. 2014; 95(12):2693-269. https:// doi.org/10.1099/vir.0.068502-0 
47. Fan S, Yuan J, Deng S, Chen Y, Xie B, Wu K, et al. Activation of Interleukin-1_Release by the Classical Swine Fever Virus Is Dependent on the NLRP3 Inflammasome, Which Affects Virus Growth in Monocytes. Front. Cell Infect Microbiol. 2018; 8:225. https://doi. org/10.3389/fcimb.2018.00225

48. Carrasco CP, Rigden RC, Vincent IE, Balmelli C, Ceppi M, Bauhofer, O, et al. Interaction of classical swine fever virus with dendritic cells. J Gen Virol. 2004; 85(6):1633-1641. https://doi.org/10.1099/vir.0.19716-0

49. Westermann B. Bioenergetic role of mitochondrial fusion and fission. Biochim Biophys Acta. 2012; 1817(10):18331838. https://doi.org/10.1016/j. bbabio.2012.02.033

50. Zorov DB, Vorobjev IA, Popkov VA, Babenko VA, Zorova LD, Pevzner, IB, et al. Lessons from the discovery of mitochondrial fragmentation (fission): a review and update. Cells. 2019; 8(2):175. https://doi. org/10.3390/cells8020175

51. Gou H, Zhao M, Xu H, Yuan J, He W, Zhu $M$, et al. CSFV induced mitochondrial fission and mitophagy to inhibit apoptosis. Oncotarget. 2017; 8(24):39382. https:// doi.org/10.18632/oncotarget.17030

52. Jingjing Pei, Jieru Deng, Zuodong Ye, Jiaying Wang, Hongchao Gou, Wenjun Liu, et al. Absence of autophagy promotes apoptosis by modulating the ROS-dependent RLR signaling pathway in classical swine fever virus infected cells. Autophagy. 2016; 12(10):1738-1758. https://doi.org/10.10 $\underline{80 / 15548627.2016 .1196318}$

53. Rehwinkel J, Gack MU. RIG-I-like receptors: their regulation and roles in RNA sensing. Nat Rev Immunol. 2020; 20(9):537-551. https:// doi.org/10.1038/s41577-020-0288-3

54. Yuan J, Zhu M, Deng S, Fan S, Xu H, Liao $\mathrm{J}$, et al. Classical swine fever virus induces pyroptosis in the peripheral lymphoid organs of infected pigs. Virus Res. 2018; 250:37-42. https://doi.org/10.1016/j. virusres.2018.04.004
55. Ma SM, Mao Q, Yi L, Zhao MQ, Chen JD. Apoptosis, autophagy, and Pyroptosis: immune escape strategies for persistent infection and pathogenesis of classical swine fever virus. Pathogens. 2019; 8(4):239. https://doi.org/10.3390/ pathogens 8040239

56. Sborgi L, Rühl S, Mulvihill E, Pipercevic J, Heilig R, Stahlberg $H$, et al. GSDMD membrane pore formation constitutes the mechanism of pyroptotic cell death. EMBO J. 2016; 35(16):1766-1778. https://doi. org/10.15252/embj.201694696

57. Fink SL, Cookson BT. Caspase-1-dependent pore formation during pyroptosis leads to osmotic lysis of infected host macrophages. Cell. Microbiol 2006; 8(11):18121825. https://doi.org/10.1111/j.14625822.2006.00751.x

58. Brown VR, Bevins SN. A review of classical swine fever virus and routes of introduction into the United States and the potential for virus establishment. Front Vet Sci. 2018; 5:31. https://doi.org/10.3389/ fvets.2018.00031

59. Coronado L, Perera $C L$, Rios L, Frías $M T$, Pérez L. A Critical Review about Different Vaccines against Classical Swine Fever Virus and Their Repercussions in Endemic Regions. Vaccines. 2021; 9(2):154. https:// doi.org/10.3390/vaccines9020154

60. Xie Z, Pang D, Yuan H, Jiao H, Lu C, Wang K, et al. Genetically modified pigs are protected from classical swine fevervirus. PLOS Pathog. 2018; 14(12):e1007193. https:// doi.org/10.1371/journal.ppat.1007193 